\title{
Cancer Risk Factors in Korean News Media: a Content Analysis
}

\author{
Su Yeon Kye ${ }^{1 \& *}$, Jeong Hyun Kwon ${ }^{2 \&}$, Yong-Chan $\mathrm{Kim}^{3}$, Minsun Shim ${ }^{4}$, Jee Hyun \\ $\mathrm{Kim}^{3}$, Hyunsoon Cho ${ }^{5,6}$, Kyu Won Jung ${ }^{5}$, Keeho Park ${ }^{2,6}$
}

\begin{abstract}
Background: Little is known about the news coverage of cancer risk factors in Korea. This study aimed to examine how the news media encompasses a wide array of content regarding cancer risk factors and related cancer sites, and investigate whether news coverage of cancer risk factors is congruent with the actual prevalence of the disease. Materials and Methods: A content analysis was conducted on 1,138 news stories covered during a 5-year period between 2008 and 2012. The news stories were selected from nationally representative media in Korea. Information was collected about cancer risk factors and cancer sites. Results: Of various cancer risk factors, occupational and environmental exposures appeared most frequently in the news. Breast cancer was mentioned the most in relation to cancer sites. Breast, cervical, prostate, and skin cancer were overrepresented in the media in comparison to incidence and mortality cases, whereas lung, thyroid, liver, and stomach cancer were underrepresented. Conclusions: To our knowledge, this research is the first investigation dealing with news coverage about cancer risk factors in Korea. The study findings show occupational and environmental exposures are emphasized more than personal lifestyle factors; further, more prevalent cancers in developed countries have greater media coverage, not reflecting the realities of the disease. The findings may help health journalists and other health storytellers to develop effective ways to communicate cancer risk factors.
\end{abstract}

Keywords: Content analysis - cancer - risk factors - news - Korea

Asian Pac J Cancer Prev, 16 (2), 731-736

\section{Introduction}

The most majority of cancers are preventable. The primary goal of cancer prevention is to avoid the development of cancer by reducing or eliminating exposure to cancer-causing factors. These factors include both environmental carcinogens and lifestyle factors, such as tobacco, alcohol, nutrition, and physical activity, which account for approximately $50 \%$ of all cancer deaths (WHO and IARC, 2003; Peto, 2011). A 2010 study found that the risk of cancer mortality is 3 times higher for individuals engaging in four specific poor health behaviors than others (Kvaavik et al., 2010). Statistically significant positive correlations were also found between cancer mortality and the percentage of the population working in metal, wood, and furniture industries (Corella et al., 2000).

The dissemination of information about cancer prevention through the news media may help to reduce the burden of cancer (Grunfeld et al., 2004). Many people become acquainted with important health care issues through the news media, demonstrating that it offers an important source of cancer prevention information (AkhuZaheya et al., 2013). How the mass media covers cancer may have important implications for cancer prevention and control. The media's portrayal of health issues over time can affect long-term secular trends in health belief, knowledge and behaviors. For example, respondents who reported higher media exposure perceived the lower level of fear of cancer and were more likely to know about the causes of cancer (Stryker et al., 2008; Jung et al., 2014). Media coverage has also been associated with changes in different cancer preventive behaviors, including smoking cessation and prevention (White et al., 2013), physical activity (Abioye et al., 2013), mammography (Yanovitzky and Blitz, 2000), cervical cancer screening (MacArthur et al., 2011), and colorectal cancer screening (Schroy et al., 2008).

Given the significant influence that cancer news coverage may have on public health practices, it is important to understand how the media is currently reporting on this issue. A recent content analysis of cancer news coverage in the United States revealed that cancer treatment was discussed more than any other aspect of cancer, including prevention, detection, survivorship, and end-of-life issues, even for highly preventable or relatively easily detected cancers; moreover, there were

${ }^{1}$ Cancer Information and Education Branch, ${ }^{2}$ Cancer Policy Branch, ${ }^{5}$ Cancer Registration and Statistics Branch, National Cancer Control Institute, ${ }^{6}$ Department of Cancer Control and Policy, Graduate School of Cancer Science and Policy, National Cancer Center, Goyang-si, ${ }^{3}$ College of Communication, Yonsei University, Seoul, ${ }^{4}$ Department of Communication and Information, Inha University, Incheon, Republic of Korea ${ }^{\circledR}$ Equal contributions*For correspondence: park.keeho@gmail.com 
Su Yeon Kye et al

discrepancies between news coverage of cancer and actual incidence or mortality rates (Slater et al., 2008). Though several studies provide insights into the nature of cancer news coverage, they are more likely to focus on: news content targeted at specific sub-populations (Stryker et al., 2007), coverage of one particular type of cancer (Atkin et al., 2008; Al-Naggar and Al-Jashamy, 2011; Bell and Seale, 2011) or one specific kind of media (Moriarty and Stryker, 2008; Smith et al., 2010). Few studies have attempted to take a comprehensive view toward news coverage of cancer risk factors and cancer sites in Korea. Consequently, this study investigates both the ways in which the news media in Korea portrays cancer risk factors of controllable environmental exposure and preventive behaviors, and the degree to which such coverage of cancer risk factors is congruent with the realities of the disease.

\section{Materials and Methods}

\section{Sample and data collection}

This study investigates cancer risk factors in four different types of media (23 news sources, including sixteen general newspapers, three major television news stations, three medical newspapers, and one news agency). To obtain a nationally representative sample, the following major media outlets have been included in this study: general newspapers (Chosun- Ilbo, Joongang-Ilbo, Dong A-Ilbo, Hankyorae-Sinmun, Kyonghyang-Sinmun, Hankuk-Ilbo, Kukmin-Ilbo, Munhwa-Ilbo, Seoul-Sinmun, Saekye-Ilbo, Maeill Business Newspaper, Seoul Business Newspaper, Asia Economy Daily, Aju Business, Money Today, and Financial News), network television news (KBS, MBC, and SBS), medical newspapers (Dailymedi, Medical Times and Yeihyub-Sinmun), and news agency (Yonhap News). The time period covered in this investigation began from January 1, 2008 to December $31,2012$.

To obtain a sample of the news stories, we used the Eyesurfer (version 3.0.), which is an online database news scrap service system in Korea. We conducted the search using a combination of the primary keyword, "cancer," with sub-keywords, "cause," "incidence," "carcinogenesis," and "engenderment." These keywords were selected based on a series of interviews with health journalists.

Six graduate student coders assisted the authors of the study in coding the content data. Pilot coding was conducted with 100 articles, none of which belonged to the final sample, to establish reliability and revise the coding scheme. Intercoder reliability was calculated using Krippendorff's alpha; all reliability test results were above 0.85 . Coding disagreements were resolved through discussion, and the resolutions were noted to ensure they were used in future coding.

Through this message selection process conducted during September 2013, 13,583 news stories were retrieved using the keyword combination as explained above. Among these stories, 1,446 were chosen through systematic stratified sampling considering the quota of ratio by the amount of news articles in each media outlet. The number of news stories for the final analysis was 1,138 , excluding the items irrelevant to cancer risk factors: for example, stories about cancer statistics $(\mathrm{N}=69)$, cancer screening $(\mathrm{N}=32)$, and cancer diagnosis or treatment $(\mathrm{N}=207)$. The unit of analysis was a single news article.

\section{Variables}

Coders first read the title and the lead of each news article to determine which cancer risk factors and cancer sites were emphasized the most. If the coders remained uncertain after this process, they read the entire story.

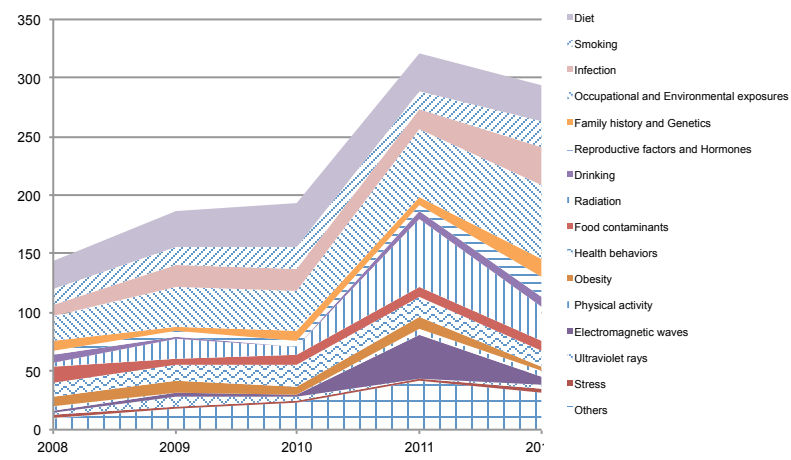

Figure 1. Cancer Risk Factor Topic Coverage

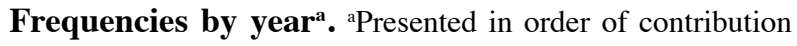
rates on World Cancer Report, 2003

Table 1. Cancer Site Coverage Frequencies by Year ${ }^{a}$

\begin{tabular}{|c|c|c|c|c|c|c|c|}
\hline \multirow{2}{*}{$\begin{array}{l}\text { Site } \\
\text { General }\end{array}$} & $\begin{array}{c}2008 \\
\mathrm{~N}(\%)\end{array}$ & $\begin{array}{c}2009 \\
\mathrm{~N}(\%)\end{array}$ & $\begin{array}{c}2010 \\
\mathrm{~N}(\%)\end{array}$ & $\begin{array}{c}2011 \\
\mathrm{~N}(\%)\end{array}$ & $\begin{array}{c}2012 \\
\mathrm{~N}(\%)\end{array}$ & \multicolumn{2}{|c|}{$\begin{array}{c}\text { Total } \\
\text { N (\%) }\end{array}$} \\
\hline & 83 (57.6) & 109 (58.6) & $108 \quad(56.0)$ & $201 \quad(62.6)$ & 172 (58.5) & 673 & $(59.1)$ \\
\hline Thyroid & $\begin{array}{ll}0 & (0.0)\end{array}$ & $(1.6)$ & $(2.1)$ & (3.1) & $(2.0)$ & 23 & $(2.0)$ \\
\hline Stomach & $2 \quad(1.4)$ & $(2.2)$ & $(2.6)$ & $(1.2)$ & $(0.7)$ & 17 & $(1.5)$ \\
\hline Colorectal & $9 \quad(6.3)$ & $(5.9)$ & $(8.3)$ & $(9.3)$ & $(4.4)$ & 79 & (6.9) \\
\hline Lung & $3 \quad(2.1)$ & $(4.8)$ & $(3.6)$ & (1.9) & $(2.7)$ & 33 & $(2.9)$ \\
\hline Liver & $1 \quad(0.7)$ & $(1.6)$ & $(1.0)$ & $(1.6)$ & $(3.1)$ & 20 & (1.8) \\
\hline Breast & 16 (11.1) & $(6.5)$ & $(3.1)$ & $(4.0)$ & 33 (11.2) & 80 & $(7.0)$ \\
\hline Prostate & $5 \quad(3.5)$ & $(2.7)$ & $(5.2)$ & $(4.0)$ & $9 \quad(3.1)$ & 42 & (3.7) \\
\hline Pancreas & $2 \quad(1.4)$ & $(0.5)$ & $(0.5)$ & $(2.5)$ & $(1.0)$ & 15 & (1.3) \\
\hline Cervical & $9 \quad(6.3)$ & $(6.5)$ & $(8.3)$ & $(2.8)$ & (7.1) & 67 & $(5.9)$ \\
\hline Skin & $2 \quad(1.4)$ & $(4.8)$ & $(3.1)$ & $(0.6)$ & $(1.7)$ & 24 & $(2.1)$ \\
\hline Others & $12 \quad(8.4)$ & $(4.3)$ & $(6.2)$ & $(6.3)$ & $(4.5)$ & 65 & $(5.8)$ \\
\hline Total & $144(100.0)$ & $186(100.0)$ & $193(100.0)$ & $321(100.0)$ & $294(100.0)$ & 1138 & $(100.0)$ \\
\hline
\end{tabular}

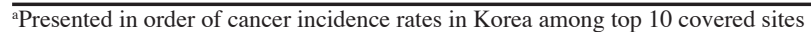


When two or more cancer risk factors or cancer sites were addressed in one news story, the more dominant one was selected and entered accordingly. The categories of risk factors, developed based on data from the World Cancer Report (WHO and IARC, 2003), included: diet, smoking, infection, occupational and environmental exposures, family history and genetics, reproductive factors and hormones, drinking, radiation, food contaminants, health behaviors, obesity, physical activity, electromagnetic waves, ultraviolet rays, stress, and others. News stories that referenced several cancer preventive behaviors were categorized as "health behaviors." The category titled "others" included pharmaceutical products, silicon, diabetes, and sexual life. The types of cancer sites coded included general cancer, thyroid, stomach, colorectal, lung, liver, breast, prostate, pancreas, cervical, skin, and others. The "others" category tapped into those not covered among the top 10 cancer types, including mouth, larynx, mesothelioma, kidney, bladder, tonsil, brain, ovary, gallbladder, esophagus, testis, and corpus uteri cancer.

\section{Analysis}

The frequencies of cancer risk factors and cancer sites in the news stories were displayed by year and media type in cross-tabulations. The cancer site coverage rankings were compared with the ranks of Korean cancer site incidence and mortality cases. The rank and proportion of cancer incidence and mortality by sites were calculated with Korean cancer registry data from 2008 to 2011, and statistics of cause of death from 2008 to 2012. The 2012 incidence data was excluded, as it had yet to be reported. Relationships between the rankings of cancer sites in the news coverage and incidence, as well as mortality, were examined using the Spearman correlation.

\section{Results}

As Figure 1 shows, occupational and environmental exposure was the most frequent topic of cancer risk factors covered by the media between 2008 and 2012, followed by diet, radiation, infection, and smoking. With respect to the differences by year, coverage of radiation dramatically increased by six times in 2011 compared to the previous year; in addition, there was a tenfold increase in the volume of stories regarding electromagnetic waves during the same period.

Table 1 reveals that more than half of the news reports covered risk factors for cancer in general, rather than for specific cancer sites. Among cancer sites, breast cancer was mentioned most frequently in news stories, followed by colorectal, cervical, and prostate cancer. News coverage on risk factors in relation to breast cancer was three times higher in 2012 compared to the previous year; likewise, news coverage on risk factors relating to skin cancer was

a) Incidence

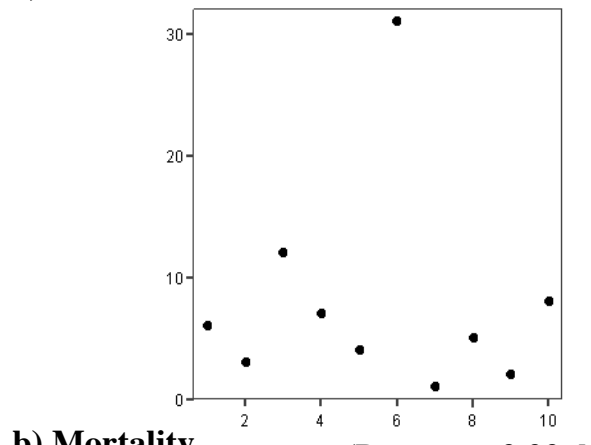

b) Mortality $\quad$ (R-square $=0.00, \mathrm{NS})$

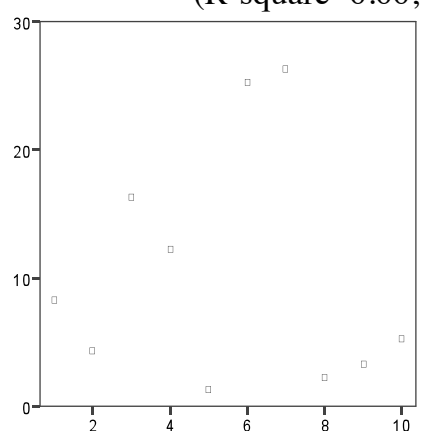

Figure 2. Relationships between the Rank of Cancer Site News Coverage and the Rank of Incidence and Mortality

\section{Table 2. Cancer Risk Factor Topic Coverage Frequencies by Type of Media}

\begin{tabular}{|c|c|c|c|c|c|c|c|c|c|}
\hline \multirow{2}{*}{$\begin{array}{l}\text { Topic } \\
\text { Diet }\end{array}$} & \multicolumn{2}{|c|}{$\begin{array}{c}\text { General newspaper } \\
\mathrm{N}(\%)\end{array}$} & $\begin{array}{l}\text { Television } \\
\mathrm{N}(\%)\end{array}$ & \multicolumn{2}{|c|}{$\begin{array}{c}\text { Medical newspaper } \\
\mathrm{N}(\%)\end{array}$} & \multicolumn{2}{|c|}{$\begin{array}{c}\text { News agency } \\
\mathrm{N}(\%)\end{array}$} & \multicolumn{2}{|c|}{$\begin{array}{l}\text { Total } \\
\mathrm{N}(\%)\end{array}$} \\
\hline & 97 & $(13.6)$ & $19(10.9)$ & 29 & $(16.2)$ & 10 & $(14.5)$ & 155 & $(13.6)$ \\
\hline Smoking & 61 & $(8.5)$ & $11 \quad(6.3)$ & 10 & $(5.6)$ & 2 & $(2.9)$ & 84 & (7.4) \\
\hline Infection & 62 & $(8.7)$ & $9 \quad(5.1)$ & 18 & $(10.1)$ & 7 & $(10.1)$ & 96 & $(8.4)$ \\
\hline Occupational and Environmental exposures & 151 & $(21.1)$ & $38(21.7)$ & 11 & $(6.1)$ & 13 & $(18.8)$ & 213 & $(18.7)$ \\
\hline Family history and Genetics & 30 & $(4.2)$ & $0 \quad(0.0)$ & 7 & $(3.9)$ & 3 & $(4.3)$ & 40 & (3.5) \\
\hline Reproductive factors and Hormones & 23 & $(3.2)$ & $4 \quad(2.3)$ & 7 & (3.9) & 1 & (1.4) & 35 & $(3.1)$ \\
\hline Drinking & 12 & $(1.7)$ & $8 \quad(4.6)$ & 3 & $(1.7)$ & 2 & $(2.9)$ & 25 & $(2.2)$ \\
\hline Radiation & 71 & $(9.9)$ & $25(14.3)$ & 10 & (5.6) & 9 & $(13.0)$ & 115 & $(10.1)$ \\
\hline Food contaminants & 23 & $(3.2)$ & $14 \quad(8.0)$ & 6 & (3.4) & 0 & $(0.0)$ & 43 & $(3.8)$ \\
\hline Health behaviors & 55 & (7.7) & $8 \quad(4.6)$ & 10 & $(5.6)$ & 2 & (2.9) & 75 & (6.6) \\
\hline Obesity & 21 & (2.9) & $4 \quad(2.3)$ & 11 & $(6.1)$ & 3 & (4.3) & 39 & (3.4) \\
\hline Physical activity & 2 & $(0.3)$ & $3 \quad(1.7)$ & 6 & (3.4) & 3 & (4.3) & 14 & $(1.2)$ \\
\hline Electromagnetic waves & 36 & $(5.0)$ & $7 \quad(4.0)$ & 5 & $(2.8)$ & 4 & (5.8) & 52 & (4.6) \\
\hline Ultraviolet rays & 16 & $(2.2)$ & $1 \quad(0.6)$ & 1 & $(0.6)$ & 0 & $(0.0)$ & 18 & (1.6) \\
\hline Stress & 4 & $(0.6)$ & $5 \quad(2.9)$ & 1 & $(0.6)$ & 0 & $(0.0)$ & 10 & $(0.9)$ \\
\hline Others & 51 & $(7.1)$ & $19(10.9)$ & 44 & $(24.6)$ & 10 & $(14.5)$ & 124 & $(10.9)$ \\
\hline Total & 715 & $(100.0)$ & $175(100.0)$ & 179 & $(100.0)$ & 69( & $(100.0)$ & 1138 & $(100.0)$ \\
\hline
\end{tabular}


Table 3. Cancer Site Coverage Frequencies by Type of Media ${ }^{\mathrm{a}}$

\begin{tabular}{|c|c|c|c|c|c|c|c|c|c|c|}
\hline \multirow{2}{*}{$\begin{array}{l}\text { Site } \\
\text { General }\end{array}$} & \multicolumn{2}{|c|}{$\begin{array}{c}\text { General newspaper } \\
\mathrm{N}(\%)\end{array}$} & \multicolumn{2}{|c|}{$\begin{array}{l}\text { Television } \\
\mathrm{N}(\%)\end{array}$} & \multicolumn{2}{|c|}{$\begin{array}{c}\text { Medical newspaper } \\
\text { N (\%) }\end{array}$} & \multicolumn{2}{|c|}{$\begin{array}{c}\text { News agency } \\
\mathrm{N}(\%)\end{array}$} & \multicolumn{2}{|c|}{$\begin{array}{l}\text { Total } \\
\mathrm{N}(\%)\end{array}$} \\
\hline & 419 & (58.6) & 124 & (70.9) & 95 & (53.1) & 35 & (50.7) & 673 & $(59.1)$ \\
\hline Thyroid & 16 & (2.2) & 2 & (1.1) & & $(2.2)$ & 1 & (1.4) & 23 & (2.0) \\
\hline Stomach & 10 & (1.4) & 1 & (0.6) & & (3.4) & 0 & $(0.0)$ & 17 & (1.5) \\
\hline Colorectal & 45 & (6.3) & 10 & (5.7) & 19 & (10.6) & 5 & (7.2) & 79 & (6.9) \\
\hline Lung & 26 & (3.6) & 5 & (2.9) & 2 & (1.1) & 0 & $(0.0)$ & 33 & (2.9) \\
\hline Liver & 13 & (1.8) & 3 & (1.7) & 3 & (1.7) & 1 & (1.4) & 20 & (1.8) \\
\hline Breast & 47 & (6.6) & 10 & (5.7) & 13 & (7.3) & 10 & (14.5) & 80 & $(7.0)$ \\
\hline Prostate & 22 & (3.1) & 3 & (1.7) & 11 & (6.1) & 6 & (8.7) & 42 & (3.7) \\
\hline Pancreas & 9 & (1.3) & 2 & (1.1) & 3 & (1.7) & 1 & (1.4) & 15 & (1.3) \\
\hline Cervical & 47 & (6.6) & 6 & (3.4) & 10 & (5.6) & 4 & (5.8) & 67 & (5.9) \\
\hline Skin & 19 & (2.7) & 2 & (1.1) & 1 & (0.6) & 2 & (2.9) & 24 & (2.1) \\
\hline Others & & (5.9) & 7 & (4.0) & 12 & (6.7) & 4 & (5.8) & 65 & (5.8) \\
\hline Total & 715 & $(100.0)$ & 175 & $100.0)$ & 179 & $100.0)$ & 69( & $100.0)$ & 1138 & $(100.0)$ \\
\hline
\end{tabular}

Table 4. Comparison of Coverage and Incidence and Mortality Cases for top 10 Most-Covered Cancer Sites in Media

\begin{tabular}{|c|c|c|c|c|c|c|c|c|c|}
\hline \multirow[t]{2}{*}{ Site } & \multicolumn{3}{|c|}{ 2008-2012 Coverage } & \multicolumn{3}{|c|}{ 2008-2011 Incidence } & \multicolumn{3}{|c|}{ 2008-2012 Mortality } \\
\hline & Rank & Cases & $\%$ & Rank & Cases & $\%$ & Rank & Cases & $\%$ \\
\hline Breast & 1 & 80 & 17.2 & 6 & 56,919 & 7.1 & 8 & 9,522 & 2.7 \\
\hline Colorectal & 2 & 79 & 17.0 & 3 & 102,925 & 12.9 & 4 & 37,580 & 10.5 \\
\hline Cervical & 3 & 67 & 14.4 & 11 & 15,445 & 1.9 & 16 & 4,738 & 1.3 \\
\hline Prostate & 4 & 42 & 9.0 & 7 & 31,000 & 3.9 & 12 & 6,594 & 1.8 \\
\hline Lung & 5 & 33 & 7.1 & 4 & 81,925 & 10.2 & 1 & 77,823 & 21.8 \\
\hline Skin & 6 & 24 & 5.1 & 31 & 1,838 & 0.2 & 25 & 1,934 & 0.6 \\
\hline Thyroid & 7 & 23 & 4.9 & 1 & 136,732 & 17.1 & 26 & 1,817 & 0.5 \\
\hline Liver & 8 & 20 & 4.3 & 5 & 64,637 & 8.1 & 2 & 62,557 & 15.7 \\
\hline Stomach & 9 & 17 & 3.6 & 2 & 120,454 & 15.0 & 3 & 49,538 & 13.9 \\
\hline Pancreas & 10 & 15 & 3.2 & 9 & 18,624 & 2.3 & 5 & 21,288 & 6.0 \\
\hline
\end{tabular}

three times higher in 2009 compared to the previous year. Coverage of risk factors for pancreas cancer was five times higher in 2011 than in 2010.

As shown in Tables 2 and 3 , there were some differences in risk factor and cancer site coverage according to the type of media. Occupational and environmental exposure was addressed as a cancer risk factor more so in general newspapers and television than in medical newspapers. Television placed a greater emphasis on radiation and food contaminants than any other type of media. In terms of cancer sites, television, more so than newspapers, dealt with risk factors for cancer in general, while neglecting more specific cancer types, such as colorectal, breast, prostate, and cervical cancer.

Table 4 and Figure 2 present comparisons between the coverage of the 10 most covered cancer sites and 20082011 incidence, as well as 2008-2012 mortality cases. In almost every cancer site, the rank of coverage was significantly different from that of actual incidence and mortality cases $(r=-0.127, p=0.726 ; r=-0.176, p=0.627)$. Breast, cervical, prostate, and skin cancer were overrepresented in the news media, whereas lung, thyroid, liver, and stomach cancer were underrepresented in comparison to incidence and mortality cases.

\section{Discussion}

This content analysis was designed to provide wideranging characteristics of news coverage, paying special attention to cancer risk factors in Korea's representative media. To our knowledge, this is the first investigation dealing with cancer risk factor news coverage in Korea. The findings show numerous disparities between cancer risk factors and cancer sites and the realities of the disease in Korea, and a different modality of coverage according to the type of media.

This research has several important implications. First, our findings suggest that the current media coverage of cancer risk factors may distort the public's perception of the importance of preventable lifestyle choices. Although lifestyle practices, such as diet and smoking, were considered as the most important cancer risk factors rather than environmental contaminants (WHO and IARC, 2003), almost one third of all cancer risk factor coverage involved occupational and environmental exposure and radiation in connection to relevant cancer incidents. By contrast, risk factors related to lifestyle were not frequently presented in news stories despite their significance. This finding suggests that the intensity of media coverage is correlated with the intensity level of actual events. Previous studies revealed that new hazards were overreported by mass media in comparison with common threats to public health (Bomlitz and Brezis, 2008). In a similar vein, our findings showed that the more ordinary the risk factors of cancer, the less likely it is to be covered by the mass media. This shortage of coverage is likely to affect the audience's accurate understanding of the issue; therefore, cancer specialists and communication 
professionals need to make efforts to develop different angles for presenting messages related to lifestyle.

In addition, one important aspect to be considered is the utility of articles concerning environmental contaminants. A previous population-based study revealed that the perceived cause of cancer risk associated with environmental pollution was lower than psychological factors and personal actions (Kye et al., 2014). This may suggest that this news mainly focus on instant upsurge of audience's interest without respect to the lasting enlightenment of the public.

Regarding the temporal trend in news coverage, while the volume of news showed an increasing tendency, the results did not reveal any long-term secular trends, This finding may be due to either the short timeframe in which this study was carried out or to the fact that cancer control policies were not modified during the research period. Notably, however, several dramatic fluctuations of coverage were found in some risk factors, for example, infection, family history and genetics, radiation, food contaminants, and electromagnetic waves; this occurred as a result of the media responding to new research results or other contemporary events. The 2008 melanin milk crisis in China caused the news articles pertaining to cancer related food contaminants to more than triple during this year. During 2011, media coverage significantly increased in response to a nuclear power plant explosion in Japan and the release of a World Health Organization report focusing on the cancer risks associated with cellphone's electromagnetic. These events also affected cancer site coverage. The death of Steve Jobs in 2011 and Michael Jackson in 2009 from cancer contributed to the rise of coverage frequencies of both pancreas and skin cancer. In addition, the personal story of female employee who died of occupational breast cancer increased news coverage related to cancer risk factors by three times. People are more influenced by, and more likely to pay attention to, risk messages concerning their health when a case history or celebrity diagnosis of cancer is included in a story rather than only medical data (Covello and Peters, 2002). However, while media attention relating to celebrities' health experiences can stimulate increased public awareness and preventive actions in the short-term, coverage tends to wane in the absence of additional news events.

Another noteworthy finding was that the media coverage of cancer risk factors differed according to the type of news media. General media, especially television, had a tendency to deliver information about accidentrelated risk factors on account of being a highly visual form of media. Similarly, past research on breast cancer news coverage showed that television mostly deals with personal stories that can attract the public's attention rather than citing evidence from public institutions or medical journals (Atkin et al., 2008). In contrast, special media, such as medical newspapers, primarily presented intensive medical articles (described in this study as "others") rather than repots relating to contemporary events. This may be because television targets a broader audience and therefore needs to deliver content that is easily understood by the general public. In regards to cancer site coverage by type of media, newspapers were more likely to write articles related to specific cancers, whereas television focused more on cancer in general and were less concerned with colorectal, prostate, and cervical cancer; this finding is in line with previous research (Slater et al., 2008). Given television is a visual form of media, reporting on these types of cancers may be seen as less appealing.

Lastly, this research implies a disparity in news coverage of specific cancer sites. Consistent with findings from several studies (Stryker et al., 2007; Slater et al., 2008; Hurley et al., 2014), breast cancer received more attention than any other specific cancer-it was the primary focus of $17.2 \%$ of coverage that dealt with particular cancer sites, followed by colorectal, prostate, cervical, and skin cancer. However, its rank among all cancers in Korea was 6 th and $8^{\text {th }}$ in terms of incidence and mortality in 2008-2011 and 2008-2012, respectively. The news attention of prostate, cervical, skin, and breast cancer was markedly over-reported when compared to other cancers. A possible explanation for the overrepresentation of these cancers could be due to successful campaigns, such as Pink Ribbon; in addition, these cancers are most common in developed countries, which has led to significant research outputs regarding prevention and screening and, consequently, increased media attention. Cancers that are more prevalent in Korea, such as thyroid, liver, and stomach cancer receive far less coverage relative to incidence and mortality cases. A content analysis examining the sources of cancer news found that the most frequently cited sources in cancer news articles were research institutions and medical journals; this implies that a positive relationship exists between research output and media articles relating to cancer (Moriarty et al., 2010). This study also shows the under-coverage of lung cancer, despite its higher mortality and incidence rate, is consistent with previous studies (Mackenzie et al., 2008). It is likely due to a common sentiment that a smoking-related disease is undeserving of public sympathy, and that smokers are responsible for their condition (Wakefield et al., 2003). Furthermore, while the theme of this study is related to risk factors, several studies have suggested that articles related to lung cancer mainly focus on diagnosis, treatment, and death instead of risk factors or prevention (Slater et al., 2008; Hurley et al., 2014).

Several limitations regarding this study should be noted with regard to interpreting research results. First, as the research focused on the period between 2008 and 2012, trends from as far back as 1999, when nation-wide cancer control policies were implemented in Korea, were not taken into account. The study only examined straightforward topics in relation to news stories. To convey actionable information that could facilitate informed decision making, future research should investigate the qualitative aspects of stories, such as core and peripheral messages, tone, and the perspective of the news. Finally, this study used data that focused solely on cancer risk factors. Identifying what point along cancer continuum has been emphasized supports the decision of view of news attention. However, as this analysis was meant to be representative of cancer risk factor news coverage in major media outlets in Korea, it demonstrates 
the disparity between news coverage and actual cancer incidence and mortality.

In conclusion, research findings suggest that coverage on risk factor topics and cancer sites was primarily affected by actual incidents regarding cancer; moreover, there were differences in reporting according to the type of media. Furthermore, the proportions of coverage dedicated to specific cancers did not accurately reflect the incidence or mortality cases for those cancers, suggesting that there is significant room for improvement in cancer risk factor news coverage in Korea. Communication professionals can draw on research results to modify strategies relating to the distribution of cancer risk factor news.

\section{Acknowledgements}

This study was financially supported by National Cancer Center (Grant 1310260-2). No potential conflicts of interest were disclosed.

\section{References}

Abioye AI, Hajifathalian K, Danaei G (2013). Do mass media campaigns improve physical activity? a systematic review and meta-analysis. Arch Public Health, 71, 20.

Akhu-Zaheya LM, Jagbir MT, Othman A, Ahram M (2013). Media use for seeking health/cancer-related information: findings from knowledge, attitudes and practices towards cancer prevention and care survey in Jordan. Int $J$ Nurs Pract, 20, 608-15

Al-Naggar RA, Al-Jashamy K (2011). Breast Breast cancer coverage in the media in malaysia: a qualitative content analysis of star newspaper articles. Asian Pac J Cancer Prev, 12, 3397-401.

Atkin CK, Smith SW, McFeters C, Ferguson V (2008). A comprehensive analysis of breast cancer news coverage in leading media outlets focusing on environmental risks and prevention. J Health Commun, 13, 3-19.

Bell L, Seale C (2011). The reporting of cervical cancer in the mass media: a study of UK newspapers. Eur J Cancer Care, 20, 389-94.

Bomlitz LJ, Brezis M (2008). Misrepresentation of health risks by mass media. J Public Health, 30, 202-4.

Corella D, Herranz C, Calatayud A, et al (2000). Cancer mortality and exposure to chemical carcinogens in the work place: an ecological study in the Valencian Community, Spain (19811995). Eur J Epidemiol, 16, 401-9.

Covello VT, Peters RG (2002). Women's perceptions of the risks of age-related diseases, including breast cancer: reports from a 3-year research study. Health Commun, 14, 377-95.

Grunfeld E, Zitzelsberger L, Evans WK, et al (2004). Better knowledge translation for effective cancer control: a priority for action. Cancer Causes Control, 15, 503-10.

Hurley RJ, Riles JM, Sangalang A (2014). Online cancer news: trends regarding article types, specific cancers, and the cancer continuum. Health Commun, 29, 41-50.

Jung M, Chan CK, Viswanath K (2014). Moderating effects of media exposure on associations between socioeconomic position and cancer worry. Asian Pac J Cancer Prev, 15, 5845-51.

Kvaavik E, Batty GD, Ursin G, Huxley R, Gale CR (2010). Influence of individual and combined health behaviors on total and cause-specific mortality in men and women: the United Kingdom health and lifestyle survey. Arch Intern Med, 170, 711-8.
Kye SY, Park EY, Oh K, Park K (2014). Perceptions of cancer risk and cause of cancer risk in Korean adults. Cancer Res Treat, [Epub ahead of print]

MacArthur GJ, Wright M, Beer H, Paranjothy S (2011). Impact of media reporting of cervical cancer in a UK celebrity on a population-based cervical screening programme. $J$ Med Screen, 18, 204-9.

Mackenzie R, Chapman S, Johnson N, McGeechan K, Holding S (2008). The newsworthiness of cancer in Australian television news. Med J Aust, 189, 155-8.

Moriarty CM, Jensen JD, Stryker JE (2010). Frequently cited sources in cancer news coverage: a content analysis examining the relationship between cancer news content and source citation. Cancer Causes Control, 21, 41-9.

Moriarty CM, Stryker JE (2008). Prevention and screening efficacy messages in newspaper accounts of cancer. Health Educ Res, 23, 487-98.

Peto R (2011). The fraction of cancer attributable to lifestyle and environmental factors in the UK in 2010. Br J Cancer, 105, 1 .

Schroy PC, Glick JT, Robinson PA, et al (2008). Has the surge in media attention increased public awareness about colorectal cancer and screening? J Community Health, 33, 1-9.

Slater MD, Long M, Bettinghaus EP, Reineke JB (2008). News coverage of cancer in the United States: a national sample of newspapers, television, and magazines. J Health Commun, 13, 523-37.

Smith KC, Kromm EE, Klassen AC (2010). Print news coverage of cancer: what prevention messages are conveyed when screening is newsworthy? Cancer Epidemiol, 34, 434-41.

Stryker JE, Emmons KM, Viswanath K (2007). Uncovering differences across the cancer control continuum: a comparison of ethnic and mainstream cancer newspaper stories. Prev Med, 44, 20-5.

Stryker JE, Moriarty CM, Jensen JD (2008). Effects of newspaper coverage on public knowledge about modifiable cancer risks. Health Commun, 23, 380-90.

Wakefield M, McLeod K, Smith KC (2003). Individual versus corporate responsibility for smoking-related illness: Australian press coverage of the Rolah McCabe trial. Health Promot Int, 18, 297-305.

White VM, Durkin SJ, Coomber K, Wakefield MA (2013). What is the role of tobacco control advertising intensity and duration in reducing adolescent smoking prevalence? Findings from 16 years of tobacco control mass media advertising in Australia. Tob Control. [Epub ahead of print]

World Health Organization, International Agency for Research on Cancer (2003). World cancer report. IARC press, Lyon.

Yanovitzky I, Blitz CL (2000). Effect of media coverage and physician advice on utilization of breast cancer screening by women 40 years and older. J Health Commun, 5, 117-34. 